\title{
CAPACITAÇÃO DOS TÉCNICOS DE ENFERMAGEM PARA AS MELHORES PRÁTICAS NO USO DE BRONCODILATADORES EM PACIENTES MECANICAMENTE VENTILADOS
}

\author{
Mara Ambrosina de Oliveira Vargas ${ }^{1}$, Cassiano Teixeira², Francine Zanchin ${ }^{3}$, Aline Ghiot ${ }^{4}$, Karine Pauli ${ }^{5}$, \\ Soraia Dornelles Schoeller ${ }^{6}$
}

\footnotetext{
${ }^{1}$ Doutora em Enfermagem. Professora Adjunto da Graduação e Pós-Graduação em Enfermagem da Universidade Federal de Santa Catarina (UFSC). Santa Catarina, Brasil. E-mail: mara@ccs.ufsc.br

${ }^{2}$ Médico Intensivista da UTI-Central do Complexo Hospitalar da Santa Casa de Porto Alegre. Professor Adjunto de Clínica Médica da Universidade Federal de Ciências da Saúde de Porto Alegre. Rio Grande do Sul, Brasil. E-mail cassiano.rush@gmail.com

${ }^{3}$ Especialista em Enfermagem em Terapia Intensiva. Enfermeira do Hospital Moinhos de Vento. Rio Grande do Sul, Brasil. E-mail: francine.zanchin@terra.com.br

${ }^{4}$ Especialista em Enfermagem em Terapia Intensiva. Enfermeira do Hospital Pereira Filho Rio Grande do Sul, Brasil. E-mail: ghiotbeck@gmail.com

${ }^{5}$ Especialista em Enfermagem em Terapia Intensiva. Rio Grande do Sul, Brasil. E-mail: karinepauli@yahoo.com.br

${ }^{6}$ Doutora em Enfermagem. Docente do Departamento de Enfermagem da Universidade Federal de Santa Catarina. Santa Catarina, Brasil. E-mail soraia@ccs.ufsc.br
}

RESUMO: A inaloterapia de broncodilatadores é uma das principais terapêuticas no tratamento de doenças respiratórias, desde que a administração seja correta para produzir uma absorção e uma ação medicamentosa efetiva. Assim, realizou-se uma pesquisa quantitativa, quase-experimental, com o delineamento pré e pós-teste, cujos objetivos foram avaliar o conhecimento dos técnicos de enfermagem na administração de broncodilatadores inalatórios, em pacientes mecanicamente ventilados, na Unidade de Terapia Intensiva, e capacitá-los para a correta aplicação desses fármacos. Com base no pré-teste, foi realizada a capacitação de 34 técnicos de enfermagem e, após, um pós-teste para a avaliação da técnica de administração dos broncodilatadores. Aplicou-se um questionário. Os resultados sinalizam que nenhum dos entrevistados descreveu, adequadamente, as etapas da nebulização no paciente mecanicamente ventilado no pré-teste. Já no pós-teste, $44,11 \%$ responderam adequadamente. Através da análise dos resultados, avaliando os pré e pós-testes, nota-se um aprendizado balizado nas melhores práticas.

DESCRITORES: Unidade de terapia intensiva. Educação em enfermagem. Ventilação mecânica. Broncodilatadores. Doenças respiratórias.

\section{QUALIFICATION OF NURSING STAFF FOR BEST PRACTICE IN THE USE OF BRONCHODILATORS IN MECHANICALLY-VENTILATED PATIENTS}

\begin{abstract}
Inhalation therapy with bronchodilators is one of the main therapeutic strategies to treat respiratory diseases as long as it is correctly executed to produce proper absorption and effective medication action. A quantitative and quasi-experimental study was conducted with a pretest and posttest design to assess the knowledge of nursing technicians concerning the administration of inhaled bronchodilators in ventilator-supported patients hospitalized in an Intensive Care Unit and also to qualify them to correctly administer these medications. A training program was administered to 34 nursing technicians based on the pretest results and afterwards, a posttest was applied to assess the technique to administer bronchodilators. Pretest was applied and none of the interviewees properly described the stages required to provide inhaled medication to mechanically ventilated patients. The stages were properly described in the posttest by $44.11 \%$ of the participants. The analysis of the results concerning both the pretest and posttests indicate the participants acquired learning based on best practices.
\end{abstract}

DESCRIPTORS: Intensive care units. Education nursing. Respiration artificial. Bronchodilatador. Respiratory tract diseases.

\section{CAPACITACIÓN DE TÉCNICOS DE ENFERMERÍA PARA MEJORAR LAS PRÁCTICAS EN EL USO DE BRONCODILATADORES EN PACIENTES MECÁNICAMENTE VENTILADOS}

RESUMEN: La Inhaloterapia con broncodilatadores, es una de las principales terapias en el tratamiento de enfermedades respiratorias, desde que la administración sea correcta para producir absorción y acción medicamentosa efectivas. Así, se realizó una pesquisa cuantitativa, casi experimental, con el delineamiento pre y pos-teste, para evaluar el conocimiento de los técnicos de enfermería sobre 
la administración de broncodilatadores inhalatorios en pacientes mecánicamente ventilados en la Unidad de Terapia Intensiva y capacitarlos para su correcta aplicación. Basado en el pre-teste, se realizó la capacitación de 34 técnicos de enfermería y, a continuación, un pos-teste para evaluar la técnica de administración de los broncodilatadores. Se aplicó un cuestionario. Los resultados señalan que ninguno de los entrevistados describió adecuadamente las etapas de la nebulización en el paciente mecánicamente ventilado en el pre-teste. Ya en el pos-teste, 44,11\% respondieron adecuadamente. El análisis de los resultados, evaluándose el pre y pos-testes, indica un aprendizaje con soporte en las mejores prácticas.

DESCRIPTORES: Unidades de terapia intensiva. Educación em enfermería. Respiración artificial. Agentes broncodilatadores. Enfermedades respiratorias.

\section{INTRODUÇÃO}

A inaloterapia é hoje uma das principais armas terapêuticas no tratamento de doenças respiratórias e estão sendo usados dispositivos cada vez mais eficazes e medicamentos com baixa incidência de efeitos colaterais. ${ }^{1-6}$ Os broncodilatadores têm como principal objetivo ativar os mecanismos que induzem relaxamento do músculo liso respiratório e também reduzem a ação dos autacóides e neurotransmissores que desencadeiam o broncoespasmo. A via preferencial para administração dos broncodilatadores é a inalatória, pois por esta via o fármaco é levado diretamente ao pulmão e vias aéreas, tornando-se efetivo em doses que causam menores efeitos adversos sistêmico. ${ }^{7}$ A broncodilatação depende de um equilíbrio entre os fatores que tendem a relaxar o músculo liso (efluxo de cálcio). O controle do tono bronquiolar é realizado pelos sistemas adrenérgicos (sistema nervoso simpático) e colinérgico (sistema parassimpático) e medicamentos que ativam (agonistas) ou que inibem (antagonistas) os neuroreceptores autômicos, sendo potencialmente importantes na terapêutica farmacológica. A estimulação parassimpática diminui o diâmetro dos brônquios e dos bronquíolos, e a estimulação simpática produz efeito contrário. Os broncodilatadores inalatórios se subdividem em: agonistas adrenérgicos (alfa e beta), como o fenoterol, salbutamol, salmeterol, e os antagonistas colinérgicos, por exemplo, o brometo de ipratrópio. ${ }^{7}$

Os broncodilatadores têm um importante significado na redução da resistência das vias aéreas, da hiperinsuflação e da dispnéia em pacientes portadores de Doença Pulmonar Obstrutiva Crônica (DPOC), asma e Auto-pressão Expiratória Positiva Final (PEEP). ${ }^{2}$ Além disso, eles aumentam a tolerância ao exercício no $\mathrm{DPOC}^{6}$, já que a redução da tolerância a exercícios e da capacidade de executar atividades laborais parece ser uma das suas maiores perdas. ${ }^{8-10} \mathrm{O}$ brometo de ipratrópio e beta-agonistas são igualmente eficazes nas exarcebações na DPOC. ${ }^{11} \mathrm{O}$ ipratrópio reduz o volume do escarro, sem alterar sua viscosidade., ${ }^{711}$

Nesta direção, os broncodilatadores inalatórios, utilizados para tratar doenças pulmonares, são práticos em sua utilização, indolores para os pacientes e eficazes ao considerarmos a alta concentração da droga oferecida. ${ }^{1}$ Os nebulizadores e o aerossol dosimetrado (dose-medida pressurizados (MDI)) acoplado ao espaçador são as formas mais eficazes para administração dos fármacos em pacientes mecanicamente ventilados, tanto entubados quanto traqueostomizados. ${ }^{1-2}$

A inalação de broncodilatadores exige uma correta administração para produzir uma absorção e uma ação medicamentosa efetiva. ${ }^{1-2}$ De outro modo, para se alcançar o efeito almejado, a técnica de administração dos fármacos inalatórios precisa ser adequadamente aplicada. Logo, ao se oferecer uma técnica inadequada compromete-se a eficácia da medicação e, consequentemente, o tratamento do paciente. ${ }^{1-4}$ A ventilação mecânica tem como objetivo levar um volume de gás até os pulmões, propiciando o ajuste da ventilação alveolar e da oxigenação arterial do paciente, obtendo valores considerados ideais. ${ }^{5}$ Neste ínterim, nos pacientes mecanicamente ventilados, as drogas inalatórias podem ser realizadas por nebulizadores por ar comprimido, nebulizadores ultra-sônicos e inaladores MDI. ${ }^{2}$

Na prática, observa-se uma deficiência na técnica de administração dos fármacos, tanto por déficit de conhecimento dos profissionais quanto por falta de treinamentos ou orientações por parte das instituições de saúde. É dessa técnica que depende a eficácia e os efeitos colaterais das medicações inaladas, de maneira que a resposta medicamentosa pode ser muito variável. Nesta perspectiva, a importância desta pesquisa reside na avaliação da técnica de administração dos broncodilatadores em pacientes mecanicamente ventilados.

Portanto, o principal questionamento relacionado a este tema e que motivou esse estudo é: os técnicos de enfermagem estão administrando corretamente os broncodilatadores inalatórios nos pacientes em ventilação mecânica? Nesse sentido, formulam-se os objetivos propostos para o estudo: avaliar o conhecimento dos técnicos de enfermagem na administração de broncodilatadores inala- 
tórios, em pacientes mecanicamente ventilados na Unidade de Terapia Intensiva (UTI), e capacitar os técnicos de enfermagem para a correta aplicação desses fármacos.

\section{MATERIAL E MÉTODOS}

Os dados foram coletados pelas pesquisadoras, na UTI do Pavilhão Pereira Filho (Complexo Hospitalar da Santa Casa de Porto Alegre), UTI especializada em doenças respiratórias, nos meses de setembro e outubro de 2007. Foi aplicado questionário aos técnicos de enfermagem da UTI, que são os responsáveis diretos pela aplicação dos broncodilatadores aos pacientes. A amostra, constituída de 34 técnicos de enfermagem, foi do tipo intencional, definida pelos seguintes critérios de inclusão dos sujeitos: (1) ter no mínimo um mês de trabalho, (2) estar em atividade no turno de trabalho no dia da aplicação do pré-teste.

O projeto foi submetido previamente à avaliação pelo Comitê de Ética em Pesquisa da Irmandade da Santa Casa de Misericórdia de Porto Alegre, obtendo autorização para desenvolvimento, sob o protocolo número 1668/07 e parecer número $382 / 07$. As condutas realizadas no estudo respeitaram a Resolução 196/96 sobre Diretrizes e Normas Regulamentadoras da Pesquisa Envolvendo Seres Humanos. ${ }^{12}$ Assim sendo, os técnicos de enfermagem receberam informações sobre os objetivos do estudo, garantia de desistência e anonimato. Após lido o Termo de Consentimento Livre e Esclarecido (pós-informado), suas dúvidas foram esclarecidas. O mesmo era composto de duas vias e, depois de assinado, uma delas ficou com o pesquisador e a outra com o pesquisado.

O estudo foi realizado dentro de uma abordagem quantitativa, quase-experimental com o delineamento pré e pós-teste. Este esquema envolve a coleta de dados em dois períodos de tempo: antes (pré-teste) da manipulação experimental e depois (pós-teste). O procedimento desse estudo incluiu três etapas: pré-teste, capacitação e pós-teste. As etapas ocorreram nos três turnos de trabalho (manhã, tarde e noite), sendo que os pesquisadores constituíram dois grupos em cada turno, totalizando seis grupos. Cada grupo participou das etapas pré-teste, capacitação e pós-teste no seu próprio turno de trabalho e em uma sala específica para capacitação localizada na UTI, em um período tempo médio entre 60 a 90 minutos, conforme demanda (tempo preenchimento do pré-teste e do pós-teste e tempo de capacitação).
Com base no pré-teste efetuou-se a capacitação que inclui informação, discussão dos conteúdos, habilidades e atitudes. Após a capacitação, aplicou-se um pós-teste para a avaliação da técnica de administração dos broncodilatadores. Logo, para o pré e o pós-teste utilizou-se um questionário estruturado com 10 perguntas abertas (Apêndice).

Os resultados são apresentados em uma tabela e em cálculos de porcentagem, a análise dos resultados é a descrição do pré-teste e do pós-teste efetuado por 34 técnicos de enfermagem da UTI em estudo. Esta análise é de tendência central, comparando-se as médias dos tópicos avaliados, descritos abaixo. Avaliaram-se as técnicas de administração dos broncodilatadores inalatórios descritas por Duarte e colaboradores: ${ }^{1}$

- técnica de administração do aerossol por MDI mais o espaçador: (1) aspirar o tubo, (2) ajustar o volume de ar corrente $>500 \mathrm{ml}$, (3) ajustar um fluxo inspiratório $<60 \mathrm{~L} / \mathrm{min}$, (4) confirmar a posição do dispositivo na alça inspiratória, (5) agitar o fármaco e instalá-lo no espaçador, (6) acionar o dispositivo no início da inspiração e (7) repetir a próxima dose 20 a 30 segundos após o primeiro jato.

- técnica de administração do aerossol por nebulizador: (1) aspirar o tubo, (2) ajustar o volume de ar corrente $>500 \mathrm{ml}$, (3) ajusta um fluxo inspiratório $<60 \mathrm{~L} / \mathrm{min}$, (4) colocar a solução no dispositivo nebulizador, (5) diluir o medicamento em 4 a 6 ml de solução fisiológica $0,9 \%$, (6) instalar o nebulizador na alça inspiratória a $30 \mathrm{~cm}$ da conexão do TET, (7) ajustar um fluxo de $6 \mathrm{~L} / \mathrm{min}$ no nebulizador, (8) bater levemente no nebulizador durante a operação e (9) desconectar o nebulizador do circuito.

\section{RESULTADOS}

No início da capacitação, percebeu-se que os técnicos de enfermagem estavam ansiosos, mesmo que o assunto versasse sobre uma técnica que faz parte de sua rotina de trabalho. Aplicou-se o pré-teste, e, após foi realizada a capacitação, com uma apresentação inicial em PowerPoint, suscitando questionamentos e discussões entre os técnicos de enfermagem e as pesquisadoras, sobre a técnica correta e como era feito até o momento. Depois de terminada a capacitação foi aplicado o pós-teste. Sinaliza-se que o questionário com as perguntas abertas, apresentado no Apêndice, está com as 
respectivas respostas, consideradas pelos autores do estudo, corretas. O objetivo desta inclusão neste artigo é propiciar informações relevantes para a boa prática assistencial.

A apresentação dos resultados das 10 questões estão demonstradas na tabela 1.

Tabela 1 - Relação da percentagem de acertos no pré-teste e no pós-teste. Porto Alegre-RS, 2007

\begin{tabular}{lcc}
\hline Questões & Pré-teste (\%) & Pós-teste (\%) \\
\hline Q1 & - & 44,11 \\
Q2 & 5,88 & 38,23 \\
Q3 & 2,94 & 88,23 \\
Q4 & 8,82 & 100 \\
Q5 & 2,94 & 17,64 \\
Q6 & - & 17,64 \\
Q7 & 88,23 & 94,12 \\
Q8 & 85,29 & 100 \\
Q9 & 70,58 & 100 \\
Q10 & 17,64 & 73,53 \\
\hline
\end{tabular}

A figura 1 apresenta a percentagem de erros detectados na oferta de broncodilatadores, através da técnica de nebulização, durante a análise individual das nove etapas do processo, no pós-teste.

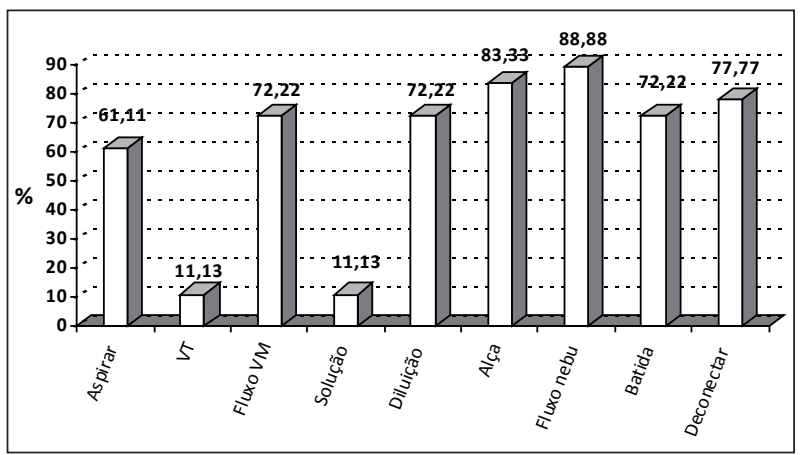

Figura 1 - Percentagem de erros na oferta de broncodilatadores por nebulização. Porto AlegreRS, 2007

A figura 2 demonstra a percentagem de erros detectados na oferta de broncodilatadores através da técnica de MDI + espaçador, durante a análise individual das sete etapas do processo, no pós-teste.

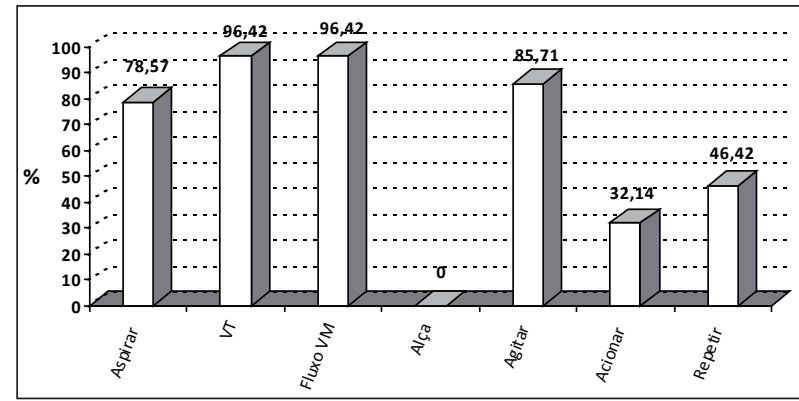

Figura 2 - Percentagem de erros na oferta de broncodilatadores na técnica de MDI. Porto Alegre-RS, 2007

Nenhum dos técnicos de enfermagem conseguiu descrever as etapas da técnica de nebulização com nebulímetro no paciente mecanicamente ventilado. Após o treinamento, no pós-teste, 44,11\% dos técnicos de enfermagem acertaram esta questão. Os 55,89\% erraram por não descreverem todos os itens da nebulização, conforme demonstrado na figura 1.

A questão número 2 do pré-teste pergunta qual o fluxo necessário de ar para realizar nebulização com nebulímetro nos pacientes intubados. Houve 5,88\% de acertos. No pós-teste os acertos aumentaram apenas para $38,23 \%$. Detectado problema de entendimento da pergunta, pois das 21 pessoas que erraram no pós-teste, 19 delas colocaram como resposta o fluxo do ventilador e 2 responderam o valor de fluxo do volume de ar corrente, em vez do fluxo do nebulímetro.

No pré-teste da questão 6, nenhum dos técnicos de enfermagem descreveu a administração do broncodilatador com espaçador corretamente, e no pós-teste, $85,36 \%$ não descreveram corretamente todas as sete etapas do procedimento, conforme mostrado na figura 2 .

Em média, 70,58\% dos funcionários, no pré-teste, sabiam que o dispositivo mais eficaz para a oferta de aerossol é o espaçador e não o nebulímetro. Já no pós-teste, todos os técnicos de enfermagem acertaram a resposta. Ainda no pós-teste, quanto à pergunta sobre o porquê do espaçador ser mais eficaz, justificaram da seguinte forma: fornecem uma dose mais confiável: $29,41 \%$; não há risco de contaminação bacteriana: $23,52 \%$; são mais eficazes: $23,52 \%$; não responderam o por quê: $14,70 \%$; e não interfere na ventilação: $8,82 \%$.

$\mathrm{Na}$ questão de número 10 foi perguntado se os parâmetros do ventilador mecânico influenciam na oferta de aerossol e por quê. No pré-teste houve $17,64 \%$ de acertos e no pós-teste esse valor 
aumentou para $73,53 \%$. Dos $26,47 \%$ das pessoas que erraram essa questão no pós-teste, $44,44 \%$ responderam que os parâmetros do ventilador mecânico influenciam na oferta de aerossol, mas não souberam explicar o porquê, 33,33\% responderam que não influenciam e também não souberam explicar o porquê e $22,22 \%$ não responderam.

\section{DISCUSSÃO}

Através dos resultados deste estudo, nota-se um aprendizado, por parte dos técnicos de enfermagem, com a capacitação sobre o uso de broncodilatadores em pacientes mecanicamente ventilados. A equipe de enfermagem recebeu orientações sobre administração de broncodilatadores, aumentando assim, seus conhecimentos e, consequentemente, propiciando ao paciente um tratamento mais eficaz. Contudo, a noção de aumentar os conhecimentos significa, aqui, entender que as atividades de enfermagem desenvolvidas são sucessivamente aprendidas e, em função disso, praticadas, alteradas e suplantadas. "O que hoje é tido como conhecimento válido é imediatamente relegado a segundo plano, ou até mesmo abandonado, à medida que um novo conhecimento passa a ser validado". ${ }^{13: 172}$

Convém destacar que as questões de número 1 e 6 exigiam a descrição detalhada dos passos a serem seguidos. Analisando as respostas dessas questões, principalmente no pós-teste, pode-se inferir de um modo mais imediato que, provavelmente, alguns técnicos de enfermagem não mostraram disposição ou paciência para respondê-las, já que suas respostas eram muito sucintas, prejudicando o resultado final. No entanto, isto suscita refletir acerca das melhores estratégias para integrar educação e trabalho. Nesta perspectiva, os resultados desta investigação, também, desencadearam nos pesquisadores, o entendimento de que o cotidiano do profissional está diretamente articulado ao sucesso ou não da transformação de uma realidade, balizada nas melhores práticas. $\mathrm{Ou}$ seja, concomitante a qualquer processo de capacitação, há necessidade da valorização da vivência diária da equipe de trabalho e do estímulo à sua consciência crítica, considerando-a como parceira na busca de resultados operacionais concretos. ${ }^{14}$

Nos pacientes intubados a distribuição do fármaco fica prejudicada. Apenas 2,9\% da medicação atinge os pulmões quando administrados por nebulizadores. $\mathrm{O}$ aerossol do MDI deve ser usado através de um adaptador ao circuito do ventilador sincronizado com a fase inspiratória. Para garantir uma dose adequada, esta deve ser duas a quatro vezes maior devido a perdas pelo circuito do ventilador. ${ }^{11}$ A adequada deposição do aerossol, nas vias aéreas inferiores, é dependente de múltiplos fatores. Entre estes múltiplos fatores estão: as propriedades físicas e químicas das medicações, a característica e posição adequada dos geradores de aerossol, os parâmetros e modos ventilatórios, o tipo de circuito ventilatório, a umidificação e aquecimento do ar inspirado, e a anatomia e presença de secreção na via aérea. ${ }^{1}$ Os pacientes com os parâmetros ventilatórios no modo assistido aumentam em 23\% a deposição do aerossol quando comparados a modos controlados, com equivalentes volume de ar corrente. Em adultos é preconizado volume de ar corrente $>500 \mathrm{ml}$ para garantir uma adequada liberação do aerossol nas vias aéreas inferiores. ${ }^{1}$ Logo, estes aspectos foram, adequadamente, inseridos como importantes pelos técnicos de enfermagem, conforme resultados da nona e décima questões.

Para além disso, constatado, pelos resultados do pré teste da sétima e nona questões, que os técnicos de enfermagem já consideravam a administração do broncodilatador por MDI e espaçador mais efetiva do que por nebulizador. Um dos possíveis motivos seria a maior facilidade da realização do procedimento em pacientes mecanicamente ventilados. Neste sentido, estudos recentes mostram que usar o espaçador comum com MDI melhora a eficácia da terapia com broncodilatadores em pacientes mecanicamente ventilados, quando a atuação de MDI é sincronizada com o início da inspiração, com cuidadosa atenção à técnica de administração. Os MDIs são fáceis de administrar, requerem menos tempo, fornecem uma dose mais confiável, e não têm risco de contaminação bacteriana; utilizando um espaçador na linha do circuito do ventilador não necessita ser desconectado, assim diminui o risco de pneumonia associada ao ventilador. ${ }^{1}$

Estudos sinalizam que os inaladores diferenciam-se quanto ao grau de deposição pulmonar, mas sua eficácia depende também da técnica de inalação e do grau de obstrução das vias aéreas. ${ }^{1,15-16}$ Quando utilizado aerossóis dosimetrados, a deposição pulmonar representa $5-10 \%$ da dose nominal liberada ao paciente. Na verdade, estudos mostram que a eficiência da oferta de aerossol ao trato respiratório inferior nos pacientes em ventilação mecânica com a utilização do nebulizador é de zero a $42 \%$ e com MDI é de 0,3 a $97,5 \% .^{1-2}$

Mas, o volume do espaçador pode afetar a 
Vargas MAO, Teixeira C, Zanchin F, Ghiot A, Paul K, Schoeller SD

disponibilidade das medicações para inalação, a qual também pode variar conforme o medicamento utilizado. Logo, os profissionais devem estar cientes de que os dados de deposição de um espaçador são provenientes de estudos com uma determinada droga, podem não se aplicar a outras drogas. ${ }^{8}$

No entanto, a quinta questão evidencia porcentagem de acerto baixa tanto no pré como no pós teste, mesmo que a resposta, paradoxalmente, parecesse simples de responder no pós teste. $\mathrm{Ou}$ seja, o nebulímetro para deposição do aerossol é mais efetivo quando colocado a uma distância de $30 \mathrm{~cm}$ do TET, em comparação ao " $\mathrm{Y}$ " do circuito e o TET. Neste caso, o circuito atua como um espaçador com acúmulo de aerossol entre as inspirações. ${ }^{1,15-16}$ Mais uma vez, este resultado pode estar demonstrando a necessidade dos pesquisadores rediscutirem com os técnicos de enfermagem a sua compreensão na importância da adequada deposição do aerossol para os pacientes que utilizam broncodilatadores.

Ainda, a quarta questão, na qual é solicitado aos técnicos de enfermagem o que deve ser feito com o nebulímetro durante a nebulização, apresentou $0 \%$ de acerto no pré-teste, o que significa que nenhum dos técnicos de enfermagem sabia o que fazer com o nebulímetro. Após o treinamento, no pós-teste, $100 \%$ das respostas estavam corretas. Neste sentido, sinaliza-se que os nebulizadores são associados com contaminação bacteriana. Levando-se em consideração tal aspecto, assim que terminada a nebulização, eles devem ser limpos e desinfectados para minimizar o risco de contaminação e de pneumonia nasocomial. O fluxo adicional do gás do nebulizador pode criar uma situação em que o paciente é incapaz de realizar o drive respiratório durante a ventilação da sustentação da pressão, podendo causar uma hipoventilação. ${ }^{1}$

\section{CONCLUSÃO}

O estudo apresenta algumas limitações: reduzido tamanho amostral, realização em único centro e ausência de acompanhamento do conhecimento dos técnicos durante os meses seguintes. Porém, os pontos fortes são: a constatação de um problema educacional comum em nosso meio, a indicação de que devemos nos ater aos modos de efetivarmos os processos de capacitação e da avaliação dos respectivos resultados, a realização do estudo em um centro de excelência em doenças respiratórias; e a descrição objetiva e criteriosa de uma forma educacional baseada em princípios internacionais.

Através dessa análise dos resultados, avaliando os pré e pós-testes, e a respectiva participação na etapa da capacitação, nota-se um aprendizado por parte dos técnicos de enfermagem sobre o uso de broncodilatadores em pacientes mecanicamente ventilados. A equipe de enfermagem recebeu orientações sobre administração de broncodilatadores, aumentando assim, seus conhecimentos e, consequentemente, possibilitando ao paciente um cuidado balizado nas melhores práticas.

A educação continuada deve ser uma prática dentro dos hospitais, pois técnicas que viram rotina, muitas vezes são esquecidas, e até mesmo ultrapassadas. Em suma, o enfermeiro é responsável técnico e ético pelos cuidados de enfermagem prestados ao paciente. Logo, deve interessar a este profissional trabalhar com uma equipe de técnicos de enfermagem competentes e cientes da necessidade de prestar um cuidado com qualidade e efetividade.

\section{APÊNDICE - QUESTIONÁRIO ESTRUTU- RADO COM PERGUNTAS ABERTAS}

\section{Adequação do uso de broncodilatadores em pacientes mecanicamente ventilados}

Questão 1) Descreva todos os passos de como você realiza a nebulização com nebulímetro no paciente mecanicamente ventilado.

Resposta esperada) Aspirar o tubo; volume de ar corrente $>500 \mathrm{ml}$; fluxo $<60 \mathrm{~L} / \mathrm{min}$; colocar a solução no dispositivo nebulizador; diluir o medicamento em 4 a $6 \mathrm{ml}$ de solução fisiológica; inserir nebulizador na alça inspiratória à $30 \mathrm{~cm}$ da conecção; observar o fluxo de $6 \mathrm{~L} / \mathrm{min}$ no nebulizador; bater levemente no nebulizador durante a operação; desconectar o nebulizador do circuito. ${ }^{1}$

Questão 2) Qual o fluxo necessário de ar para realizar nebulização com nebulímetro nos pacientes entubados? ${ }^{1}$

Resposta esperada) 6 a $81 / \mathrm{min}$.

Questão 3) Qual o volume correto da solução para ser colocado no nebulizador efetivando a nebulização em pacientes mecanicamente ventilados?

Resposta esperada) 4 a $6 \mathrm{ml}^{1}{ }^{1}$

Questão 4) O que deve ser feito no nebulímetro durante a nebulização? 
Resposta esperada) Bater levemente no nebulímetro. ${ }^{1}$

Questão 5) Qual é a melhor posição do nebulizador no circuito do ventilador para ser eficaz o procedimento?

Resposta esperada) Estar na vertical e a $30 \mathrm{~cm}$ do Tubo Endo Traqueal (TET). ${ }^{1,11}$

Questão 6) Descreva como você realiza a administração de broncodilatadores com espaçador no paciente mecanicamente ventilado.

Resposta esperada) Aspirar o tubo; observar e manter volume de ar corrente $>500 \mathrm{ml}$; observar e manter fluxo $<60 \mathrm{~L} / \mathrm{min}$; confirmar dispositivo na alça inspiratória; agitar o fármaco e instalá-lo no espaçador; acionar no início da inspiração; repetir dose 20 a 30s depois; observar a posição correta ventilador - filtro - espaçador. ${ }^{1}$

Questão 7) Qual fase da respiração deve-se realizar o jato no espaçador quando administrado os fármacos inalatórios (bombinhas)?

Resposta esperada) Inspiratória. ${ }^{1-6}$

Questão 8) O que devemos fazer com o frasco do fármaco inalatório antes de administrá-lo no espaçador?

Resposta esperada) Agitar. ${ }^{1}$

Questão 9) Na sua opinião, você acha mais eficaz a oferta de aerossol por qual dispositivo e por quê? Resposta esperada) Fármaco pelo espaçador. Porque são mais eficazes, mais fáceis de administrar, requerem menos tempo, fornecem uma dose mais confiável e não tem risco de contaminação bacteriana. ${ }^{1-11}$

Questão 10) Na sua opinião, os parâmetros do ventilador mecânico influenciam na oferta do aerossol e por quê?

Resposta esperada) Sim. Porque os parâmetros ventilatórios no modo assistido aumentam em $23 \%$ a deposição do aerossol quando comparado a modos controlados. É necessário volume de ar corrente $>500 \mathrm{ml}$ para garantir uma adequada liberação do aerossol nas vias aéreas inferiores. ${ }^{11}$

\section{REFERÊNCIAS}

1. Duarte AG. Inhaled bronchodilator administration during mechanical ventilation. Respir Care. 2004 Jun; 49(6):623-33.

2. Dolovich MB, Ahrens RC, Hess DR, Anderson P, Dhand R, Rau JL, et al. Device selection and outcomes of aerosol therapy: evidence-based guidelines: American College of Chest Physicians/American
College of Asthma, Allergy and Immunology. Chest. 2005 Jan; 127(1): 335-71.

3. Guerin C, Fassier T, Bayle F, Lemansson S, Richard JC. Inhaled bronchodilator administration during mechanical ventilation: how to optimize it, and for which clinical benefit? J Aerosol Med Pulm Drug Deliv. 2008 Mar; 21(1):85-96.

4. MacLoughlin RJ, Higgins BD, Laffey LG, O'Brien T. Optimized aerosol delivery to a mechanically ventilated rodent. J Aerosol Med Pulm Drug Deliv. 2009 Dec; 22(4):323-32.

5. Franca AS, Carvalho CR. Ventilação Mecânica In: Silva LCC, Teixeira PJZ, organizadores. Doenças respiratórias graves. Rio de Janeiro (RJ): Revinter; 2003. p. 90-7.

6. Rocha Filho W, Noronha VX, Senha SN, Simal CJ, Mendonça WB. Avaliação da influência da idade e do volume do espaçador na deposição pulmonar de aerossóis. J Pediatria. 2004 Set-Out; 80(5): 387-90.

7. Wise RA. Chronic obstructive pulmonary disease: clinical course and management. In: Fishman AP, et al. Fishman's pulmonary disease and disorders. $4^{\mathrm{a}}$ ed. New York: McGraw-Hill; 2008. p. 729-46.

8. Rivera-Fernández R, Navarrete-Navarro $P$, Fernández-Mondejar E, Rodriguez-Elvira $M$, Guerrero-López F, Vázquez-Mata G, et al. Six-year mortality and quality of life in critically ill patients with chronic obstructive pulmonary disease. Crit Care Med. 2006 Sep; 34(9):2317-24.

9. Iribarren-Diarasarri S, Aizpuru-Barandiarana F, Loma-Osorio A, Castedo-González J, Poveda-Hernández Y, Muñoz-Martínez T, et al. Factores pronósticos de mortalidad en pacientes con enfermedad pulmonar obstructiva crónica tras su ingreso en una Unidad de Medicina Intensiva. El papel de la calidad de vida. Med Intensiva. 2005; 29(4):204-11.

10. Teixeira C, Cabral CR, Hass JS, Oliveira RP, Vargas $\mathrm{MAO}$, Freitas APR, et al. Exacerbação aguda da DPOC: mortalidade e estado funcional dois anos após a alta da UTI. J Bras Pneumol. 2011 Mai-Jun; 37(3):334-40.

11. Teixeira PJZ, Meregalli AF, Becker A. Manejo do paciente com asma aguda grave. In: Silva LCC, Teixeira PJZ, organizadores. Doenças respiratórias graves. Rio de Janeiro (RJ): Revinter; 2003. p:165-72.

12. Ministério da Saúde (BR), Conselho Nacional de Saúde, Comissão Nacional de Ética em Pesquisa. Resolução n 196 de 10 outubro de 1996: diretrizes e normas regulamentadoras de pesquisa envolvendo seres humanos. Brasília (DF): MS; 1996.

13. Vargas MAO, Ramos FRS. Tecnobiomedicina: implicações naquilo e daquilo que a enfermagem faz em terapia intensiva. Texto Contexto Enferm. 2008 Jan-Mar; 17(1):168-76.

14. Backes VMS, Lino MM, Prado ML, Reibnitz KS, Conaver BP. Competências dos enfermeiros na atuação como educador em saúde. Rev Bras. Enferm. 
2008 Nov-Dez [acesso 2012 Mai 2]; 61(6). Disponível em: http://www.scielo.br/scielo.php?script=sci arttext\&pid=S0034-71672008000600011\&lng=en\& $\mathrm{nrm}=\mathrm{iso}$

15. Tietze KJ, ManakerS. Pulmonary pharmacotheraphy. In: Fishman AP. Fishman's Pulmonary Disease and
Disorders. $4^{\text {a }}$ ed. New York (US): McGraw-Hill; 2008. p. 2631-44.

16. Moura RS. Farmacologia do sistema respiratório. In: Bethlem N. Pneumologia. $4^{a}$ ed. São Paulo (SP): Atheneu; 2000. p. 55-63. 